\title{
New records of octocorals (Cnidaria: Anthozoa) from the Brazilian coast
}

\author{
Carlos D. Pérez ${ }^{1, *}$, Bárbara M. Neves ${ }^{1}$, David H. R. Oliveira ${ }^{2}$ \\ ${ }^{1}$ GPA-CAV, Universidade Federal de Pernambuco, CEP: 55608-680, Vitória de Santo Antão, PE, Brazil \\ ${ }^{2}$ Mestrado em Biologia Animal, Departamento de Zoologia-CCB, Universidade Federal de Pernambuco, CEP: 50670-420, \\ Recife, PE, Brazil
}

\begin{abstract}
The Oceanography Department of the Federal University of Pernambuco (DOCEANUFPE) possesses a large collection of octocoral samples from the Brazilian coast; most of which were collected during expeditions carried out on the oceanographic ships 'Akaroa,' 'Almirante Saldanha,' 'Antares,' 'Calypso,' and 'Canopus' between 1965 and 1971. This paper focuses on 7 new octocoral records that resulted from these surveys, of which 5 are first records for South Atlantic waters: Leptogorgia stheno (Bayer, 1952), Muriceopsis bayeriana Sánchez, 2007, Muriceopsis flavida Bayer, 1961, Chironephthya sp., and Thelogorgia studeri Bayer, 1992; the last species is also the first record of the Family Keroeididae for the region. Additionally, Nidalia occidentalis Gray, 1835 was recorded for the first time in Brazil, while the genus Nidalia was a first time record for northern Brazil. All of these records highlight the importance of sampling carried out by oceanographic expeditions in filling some of the gaps in the geographic distribution of certain taxa, thus increasing the knowledge of marine biodiversity in the locations studied.
\end{abstract}

KEY WORDS: Octocorallia · Alcyonacea · Geographic distribution · South Atlantic Ocean Resale or republication not permitted without written consent of the publisher

\section{INTRODUCTION}

There are approximately 3000 species of extant octocorals known worldwide (Daly et al. 2007), yet only over 100 species and/or morphotypes have been recorded in Brazil (Castro et al. 2010). Most of the records for this country date back to the late 19th to early 20th centuries; thus, few related data are available in journals, but there are abundant records in grey literature such as in MSc and $\mathrm{PhD}$ dissertations (Castro et al. 2010).

The Oceanography Department of the Federal University of Pernambuco (DOCEAN), Brazil, has many octocoral samples that have been collected since 1961 during oceanographic expeditions carried out along the Brazilian coast. Although this material has been kept in storage for many years, recent analyses have revealed new records for the South Atlantic and for Brazil. These new records are listed and discussed in the present study.

\section{MATERIALS AND METHODS}

The samples were collected along the Brazilian coast by the Oceanographic Institute of Recife during expeditions carried out by the following oceanographic ships between 1965 and 1971: 'Akaroa,' 'Canopus,' 'Geomar' II and III, 'ITA,' 'Norte/Nordeste' I and II, and 'Recife.'

Samples were taken mainly by dredging sandy or muddy bottoms and by trawling. Rectangular dredges were used, either with 601 ('Akaroa,' 'Canopus,' 'Recife') or 1201 capacity ('Geomar' and 'Norte/ Nordeste'). After part of the samples were separated for geological study, they were washed using sieves, and the biological components were then isolated (Kempf 1970). The material studied was conserved in $70 \%$ alcohol and deposited in the DOCEAN invertebrate collection.

Sclerites were analyzed in temporary glass slides, and some were observed under a scanning electron 
microscope (Hitachi S 405-A). Sclerites were then measured under an optic microscope using an eyepiece micrometer. Terminology follows Bayer et al. (1983).

\section{RESULTS}

Seven taxa from 4 families within the Order Alcyonacea were identified. Five taxa are reported for the first time for the South Atlantic and for Brazil; one is a first record for Brazil and one for the country's northern region.

\section{Family Gorgoniidae Lamouroux, 1812}

Genus Leptogorgia Milne Edwards and Haimes, 1857 Leptogorgia stheno (Bayer, 1952) (Fig. 1A-G)

Diagnosis. See Bayer (1961).

Material examined. Oceanographic survey 'Norte/ Nordeste I', Stn 1787 (2 samples, 032 27' N, 50 15’ W, $66 \mathrm{~m}$, 1967, CNI-DOCEAN nos. 678 and 679); 'Norte/Nordeste I,' Stn 1794 (1 sample, 0408' N, $50^{\circ} 35^{\prime} 30^{\prime \prime} \mathrm{W}, 52 \mathrm{~m}, 1967$, CNI-DOCEAN no. 680); 'Norte/Nordeste II,' Stn 1889 (1 sample; 00²3' S, $47^{\circ} 16^{\prime} 06^{\prime \prime} \mathrm{W}, 31 \mathrm{~m}, 1968$, CNI-DOCEAN no. 681).

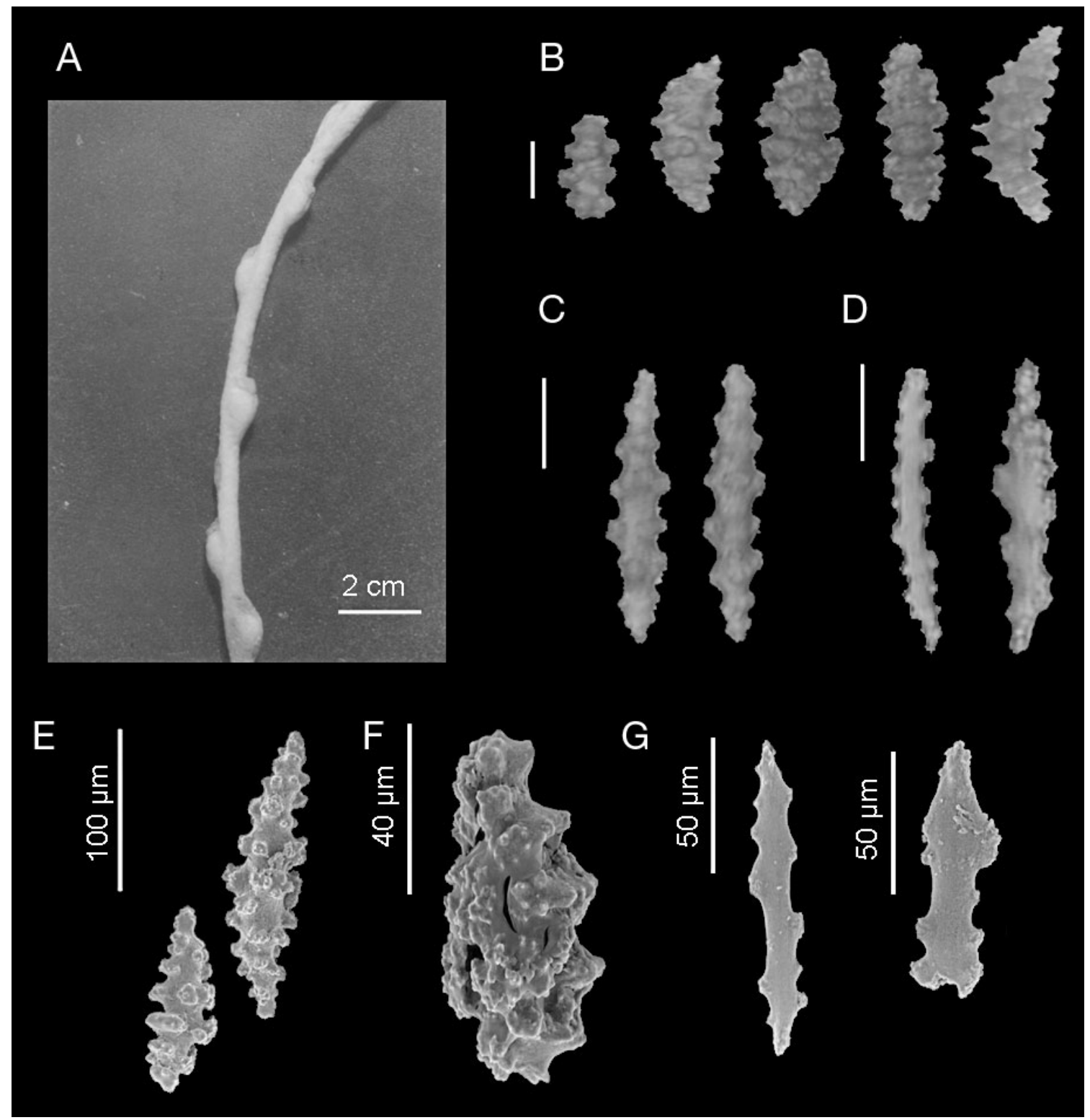

Fig. 1. Leptogorgia stheno (Bayer, 1952). (A) Branch of colony; (B) capstans and spindles from outer cortex; (C) spindles from inner cortex; (D) rods from anthocodiae; (E-G) SEM: (E) spindles; (F) capstan; (G) rods from anthocodia 
Description. Whip-shaped, unbranched colonies, without attachments, and with extremely slender stems (0.36-0.6 mm; Fig. 1A). Polyps separated and alternated along 1 series. Colony height 6 to $14 \mathrm{~cm}$. Outer cortex with spindles mostly warted, sometimes curved, 0.10 to $0.18 \mathrm{~mm}$ long, but also smaller capstans (Fig. 1B). Inner cortex with spindles and rods less ornate than in the outer cortex (Fig. 1C). Distinct anthocodial armature, bearing rods with scalloped edges, 0.10 to $0.13 \mathrm{~mm}$ long (Fig. 1D, G). Pinnules with thin rods. Colors: brown, beige, and orange.

Distribution. From Palm Beach (Florida) to the Alabama, USA, coast; Gulf of Mexico (Bayer 1952); Bocas del Toro (Panama; Sánchez \& Wirshing 2005); Surinam (Bayer 1959). This the first record of this species for the Brazilian coast (states of Amapá and Para) and for the South Atlantic Ocean (Fig. 2); it shows continuity in its distribution, as Amapá borders Dutch Guiana.

Remarks. There are 2 other species of the genus Leptogorgia that are comparable to L. stheno, both described by Bayer (1952): L. euryale and L. medusa. They have a strong anthocodial armature with rods that reach or exceed $2 / 3$ of the length of the longest spindles in the rind (Bayer 1961). These species are discernible mainly because $L$. stheno has extremely slender branches and polyps alternating in 1 series, while $L$. medusa has closely spaced polyps; additionally, L. euryale has stouter branches than L. stheno, but with widely separated polyps.

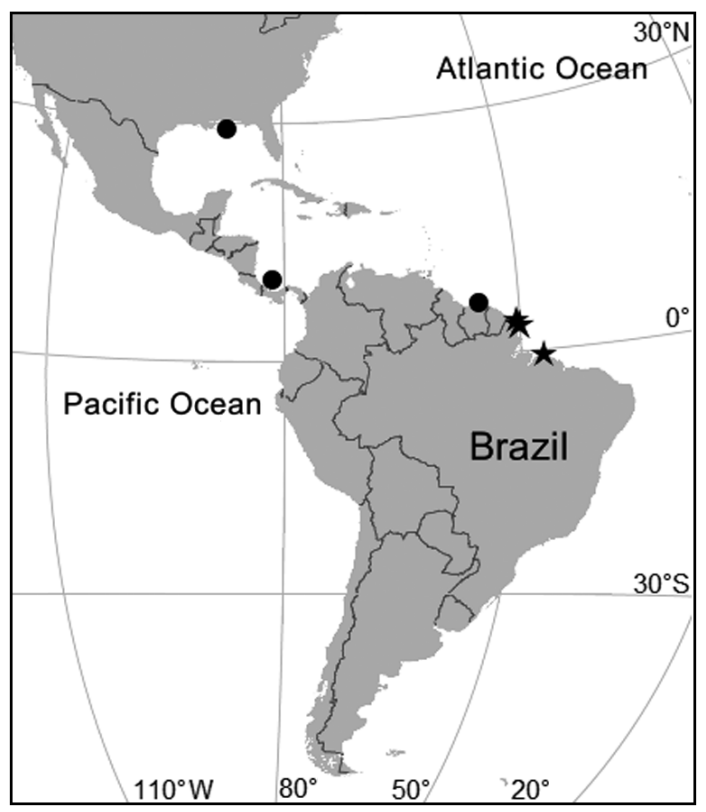

Fig. 2. Leptogorgia stheno. Distribution. (•) Previous records; $(\star)$ this study

\section{Family Keroeididae Kinoshita, 1910}

Diagnosis. Colony with erect, rigid axis consisting of a central cord and a cortical layer of smooth sclerites united by a horny matrix. Retractile polyps in moderately developed calyces (Kinoshita 1910). Central core chambered; thickly plated sclerites in outer rind, in the anthocodiae small and bifurcate, shaped like crutches (Bayer 1956).

Remarks. The Family Keroeididae encompasses 5 genera (Daly et al. 2007): Lignella Gray, 1870 (possibly invalid; see Bayer 1992 p. 507-508); Keroeides Studer, 1887; Thelogorgia Bayer, 1992; Ideogorgia Bayer, 1981, and Pseudothelogorgia van Ofwegen, 1994. The genus Keroeides is known from Hawaii (Bayer 1956), the Bikini Atoll (Bayer 1949), the Somali coast (van Ofwegen 1990), New Caledonia, the Red Sea, Mayotte, the Mollucas (Indonesia), Japan, Palau, New Guinea, Funafuti (Tuvalu), Northern Australia, and the Northern Mariana Islands (Fabricius \& Alderslade 2001); Ideogorgia is found in South Africa (Williams 1992) and Alaska (cf. Ideogorgia; Wing \& Barnard 2004); Pseudothelogorgia has only been recorded off the Indian coast (van Ofwegen 1994); finally, the genus Thelogorgia has only been recorded for Caribbean waters (Bayer 1992).

\section{Thelogorgia studeri Bayer, 1992 (Fig. 3A-G)}

Diagnosis. See Bayer (1992).

Material examined. Oceanographic survey 'Norte/ Nordeste I', Stn 1778 (2 samples; 03 00' N, 48²0' W, 117 m, 1967, CNI-DOCEAN nos. 407 and 408); oceanographic survey 'Norte/Nordeste I', Stn 1813 (1 sample; $01^{\circ} 29^{\prime} \mathrm{S}, 43^{\circ} 19^{\prime} \mathrm{W}, 83 \mathrm{~m}, 1967$, CNI-DOCEAN no. 409).

Description. Colonies ramified and extremely delicate; polyp distribution biserial, alternate, sometimes opposite, with conspicuous longitudinal grooves at the cortex (Fig. 3A). Polyps slightly star-shaped, 2 to $3.5 \mathrm{~mm}$ high, wider at the distal region $(0.75-$ $1.38 \mathrm{~mm}$ ) and slender at the proximal region (0.42$0.55 \mathrm{~mm}$; Fig. 3B). Branch width 0.4 to $0.475 \mathrm{~mm}$. Hollow axis surrounded by smooth, irregular sclerites $(0.25$ to $0.3 \mathrm{~mm}$ in height; Fig. 3C, D). Cortex with elongated spindles and average height of 0.3 to $0.48 \mathrm{~mm}$ (Fig. 3E). Calyces with elongated spindles at the column (0.30-0.36 $\mathrm{mm})$ and points $(0.27-0.47 \mathrm{~mm})$. Warted sclerites at the back of the tentacles, curved near one end (Fig. 3F), 0.15 to $0.28 \mathrm{~mm}$ long and 0.02 to $0.07 \mathrm{~mm}$ wide. Color: beige.

Distribution. Southward of the Bahamas to the Greater Antilles and the northwestern part of the 


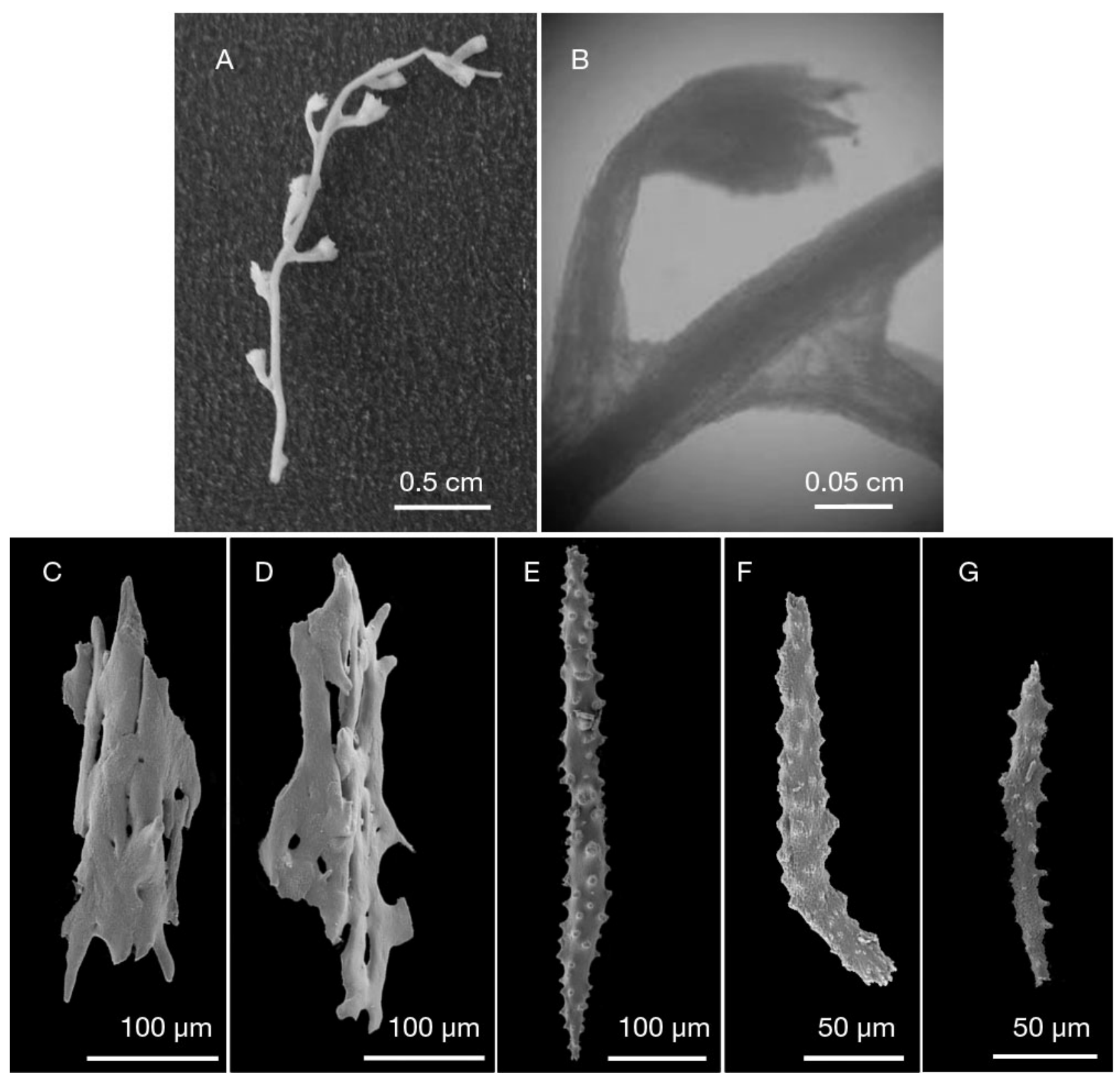

Fig. 3. Thelogorgia studeri Bayer, 1992 (CNI-DOCEAN no. 407). (A) Fragment; (B) polyp; (C-G) SEM: (C) sclerites from axis; (E) cortex; (F) back of tentacles; (G) tentacles (pinules)

Caribbean Sea, and southward to the Caribbean coast of South America, 12 to $82 \mathrm{~m}$ deep (Bayer 1992). This is the first record of Thelogorgia studeri in Brazil; it is also the first record of the Family Keroeididae in South Atlantic waters, state of Maranhão, Brazil (012 $29^{\prime} \mathrm{S}, 43^{\circ} 19^{\prime} \mathrm{W}$; Fig. 4).

Remarks. Despite the 2 to $3 \mathrm{~mm}$ high polyps of the specimens analyzed herein, the other features match the species' description (e.g. slender sclerites on the back of the tentacles; crosses absent from the main stem; presence of spindles in the cortex). Addition- ally, the height of the polyps may be related to the degree that they contracted during preservation.

Bayer (1992) separated species of this genus into 2 groups: 2 species with contracted polyps, less than $4 \mathrm{~mm}$ high and with points that form a distinct stellate figure (Thelogorgia stellata Bayer 1992 and T. studeri Bayer 1992), and 2 species with contracted polyps, 4 to $6 \mathrm{~mm}$ high and whose calyces do not have a distinct stellate shape ( $T$. longiflora Bayer 1992 and T. vossi Bayer 1992). Within the first group, $T$. studeri is different from $T$. stellata mainly because 


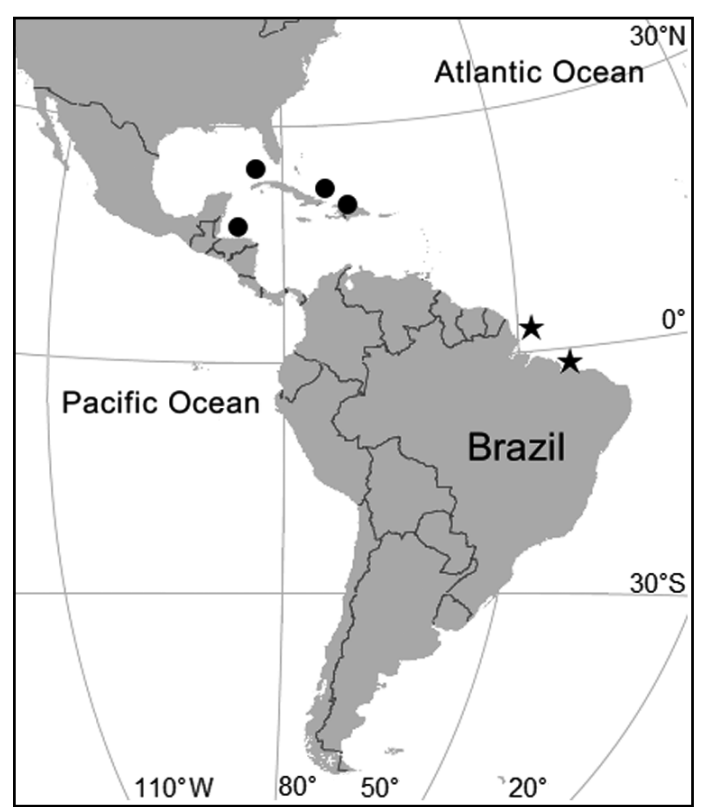

Fig. 4. Thelogorgia studeri Bayer, 1992. Distribution. $(\bullet)$ Previous records; $(\star)$ this study

of the slender sclerites on the back of its tentacles and polyps that are smaller (1-2 mm high) than those of T. stellata $(2.5-3.5 \mathrm{~mm})$.

\section{Family Plexauridae Gray, 1859}

Genus Muriceopsis Aurivillius, 1931

Muriceopsis bayeriana Sánchez, 2007 (Fig. 5A-C)

Diagnosis. See Sánchez (2001).

Material examined. Oceanographic survey 'Itamaracá,' Stn 18 (1 sample; Paraiba coast, 1969, CNIDOCEAN no. 744).

Description. Colonies arborescent, bushy, and stout (Fig. 5A), 7 to $11.5 \mathrm{~cm}$ long, 6 to $10 \mathrm{~cm}$ wide. Polyps very close, along the entire colony. Calyces rounded, prominent. Outer cortex with warted, stout, and spiny sclerites (average length $0.4 \mathrm{~mm}$; Fig. 5B). Medium cortex with spindles ca. $0.63 \mathrm{~mm}$ long. Axial sheath with evident layer of elongated, colorless spindles, $0.3 \mathrm{~mm}$ long (Fig. 5C). Purple sclerites not observed. Color: yellowish.

Distribution. Costa Rica, Panama, and the Uraba Gulf (Colombia; Sánchez 2001). This is the first record for the Brazilian coast (state of Paraíba), as well as the first record for this species in the South Atlantic Ocean (Fig. 6).

Remarks. Sánchez (2001) described Muriceopsis bayeri as a new species, but this name had already been used by Tixier-Durivault and d'Hondt in 1974. The species found by Sánchez was a junior homonym; therefore, that author changed the specific name to Muriceopsis bayeriana Sánchez, 2007. Conversely, the Tixier-Durivault \& d'Hondt (1974) specimens identified as $M$. bayeri were in fact Muriceides sceptrum (Studer 1890) (Grasshoff 1977). Among the other species described for the genus Muriceopsis, the most similar to Muriceopsis bayeriana is Muriceopsis sulphurea (Donovan 1825), yet it can be distinguished from Muriceopsis bayeriana due to the nudibranch-shaped sclerites in the outer cortex, with large unilateral spines. Muriceopsis petila has very elongated spindles in the outer cortex, which can surpass $1 \mathrm{~mm}$ in length; colonies are sparsely ramified and pinnate, and calyces are mere elevations in the coenenchyma (Sánchez 2001). Muriceopsis flavida also has large spindles in the outer cortex that reach $0.6 \mathrm{~mm}$ in length; its colonies are pinnate, with branches separated from one another (Sánchez 2001).

Considering the great variation in the outer cortex sclerites of Muriceopsis bayeriana, Castro et al.

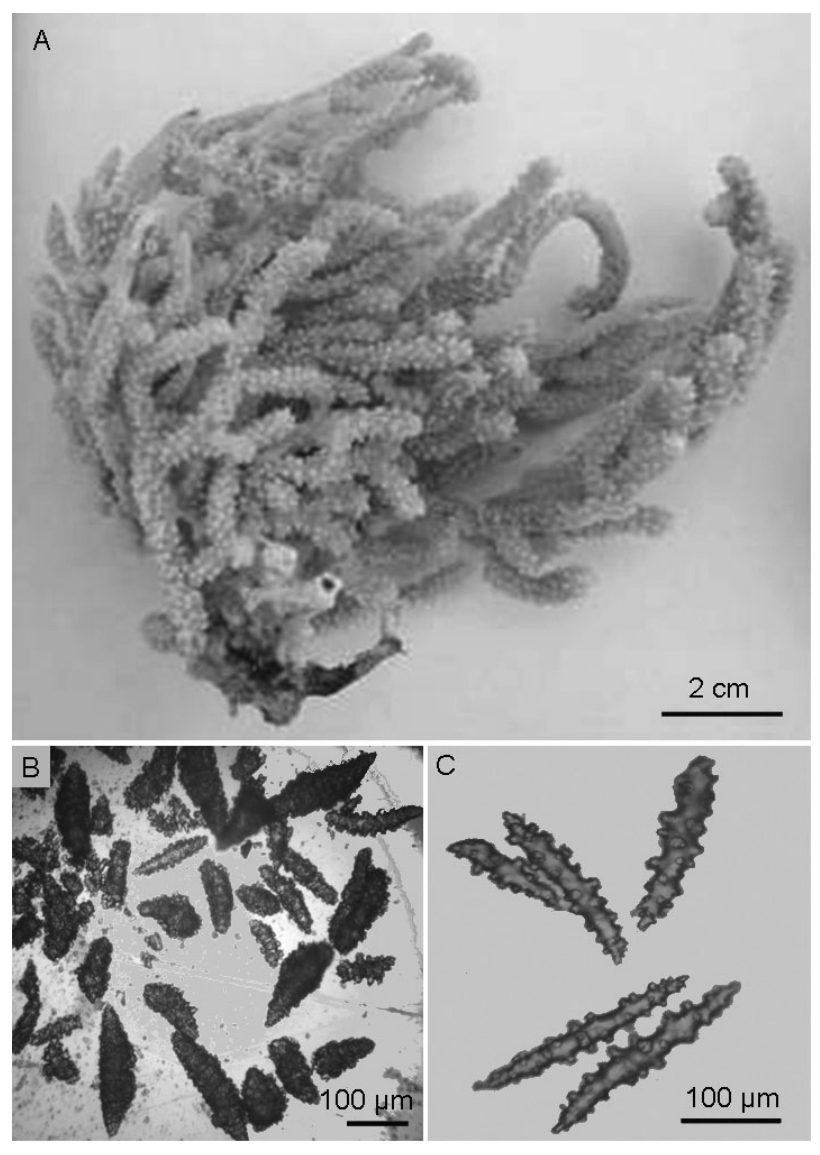

Fig. 5. Muriceopsis bayeriana Sánchez, 2007 (CNI-DOCEAN no. 744). (A) Colony; (B) sclerites from outer cortex; (C) inner cortex 


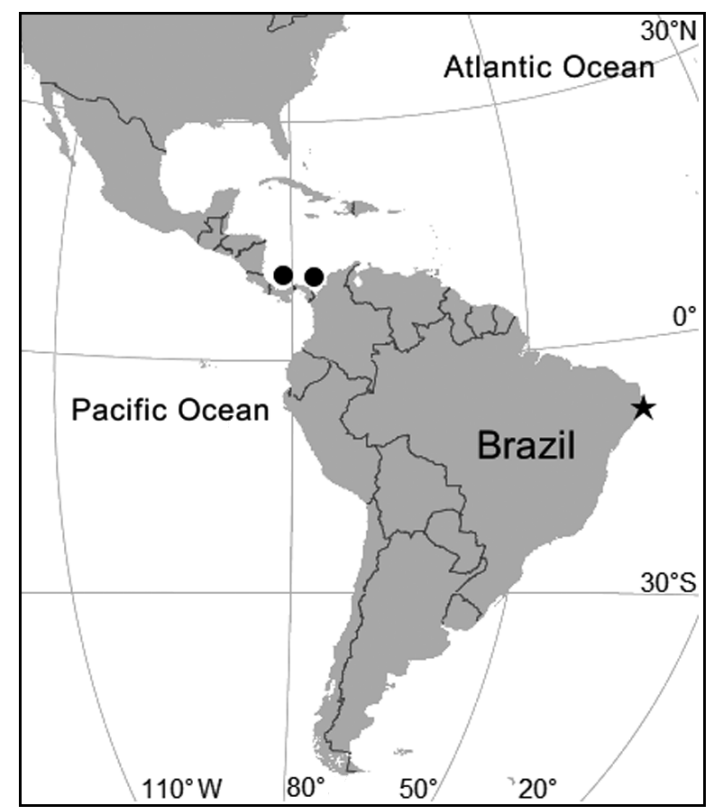

Fig. 6. Muriceopsis bayeriana Sánchez, 2007. Distribution. $(\bullet)$ Previous records; $(\star)$ this study

(2010) cited it as a possible synonym of $M$. sulphurea. Nevertheless, herein we chose to keep them as separate species, and the specimens were identified as $M$. bayeriana, mainly due to the presence of generally small, stouter spindles on the outer cortex. It is neces- sary to analyze several Muriceopsis specimens collected along the Brazilian coast in order to uncover variation within the same species or to confirm the existence of different species.

Muriceopsis flavida (Lamarck, 1815) (Fig. 7A-D)

Diagnosis. See Sánchez (2001).

Material examined. Oceanographic survey: 'Akaroa' Stn 2 (1 sample; 08 56' 12" S, 3502' 42" W, 32 m, 1965, CNI-DOCEAN no. 745); 'Akaroa' Stn 24 (1 sample, 09 15' 42" S, 34 59' 12" W, 49 m, 1965, CNI-DOCEAN no. 746); 'Akaroa' Stn 35 (1 sample, $09^{\circ} 27^{\prime} 48^{\prime \prime} \mathrm{S}, 35^{\circ} 07^{\prime} 42^{\prime \prime} \mathrm{W}, 32 \mathrm{~m}, 1965$, CNI-DOCEAN no. 747); 'Recife' Stn 147 (1 sample, 08 00' S, $32^{\circ} 09^{\prime} \mathrm{W}$, $51 \mathrm{~m}$, CNI-DOCEAN no. 748); 'Norte/ Nordeste I' Stn 1743 (1 sample, 0051' S, 4341' W, 75 m, CNI-DOCEAN no. 749).

Description. Colonies pinnate, with opposite or alternating slender and sparse branches (separated $\geq 1 \mathrm{~cm}$ from one another; Fig. 7A). Polyps distributed along entire colony, with conspicuous calyces. Colonies 9.5 to $30.5 \mathrm{~cm}$ long, 3 to $11 \mathrm{~cm}$ wide; stem diameter 0.1 to $0.3 \mathrm{~cm}$ (wider at the base). Outer cortex spindles medium in length $(0.47-0.59 \mathrm{~mm}$; Fig. 7B), but can reach $0.78 \mathrm{~mm}$ (rare; Fig. 7D). Medium axial sheath with purple spindles (0.28-0.37 mm; Fig. 7C); smaller ones rare $(0.21 \mathrm{~mm})$. Anthocodial sclerites are spiny rods on average ca. $0.16 \mathrm{~mm}$ long. Color: beige.
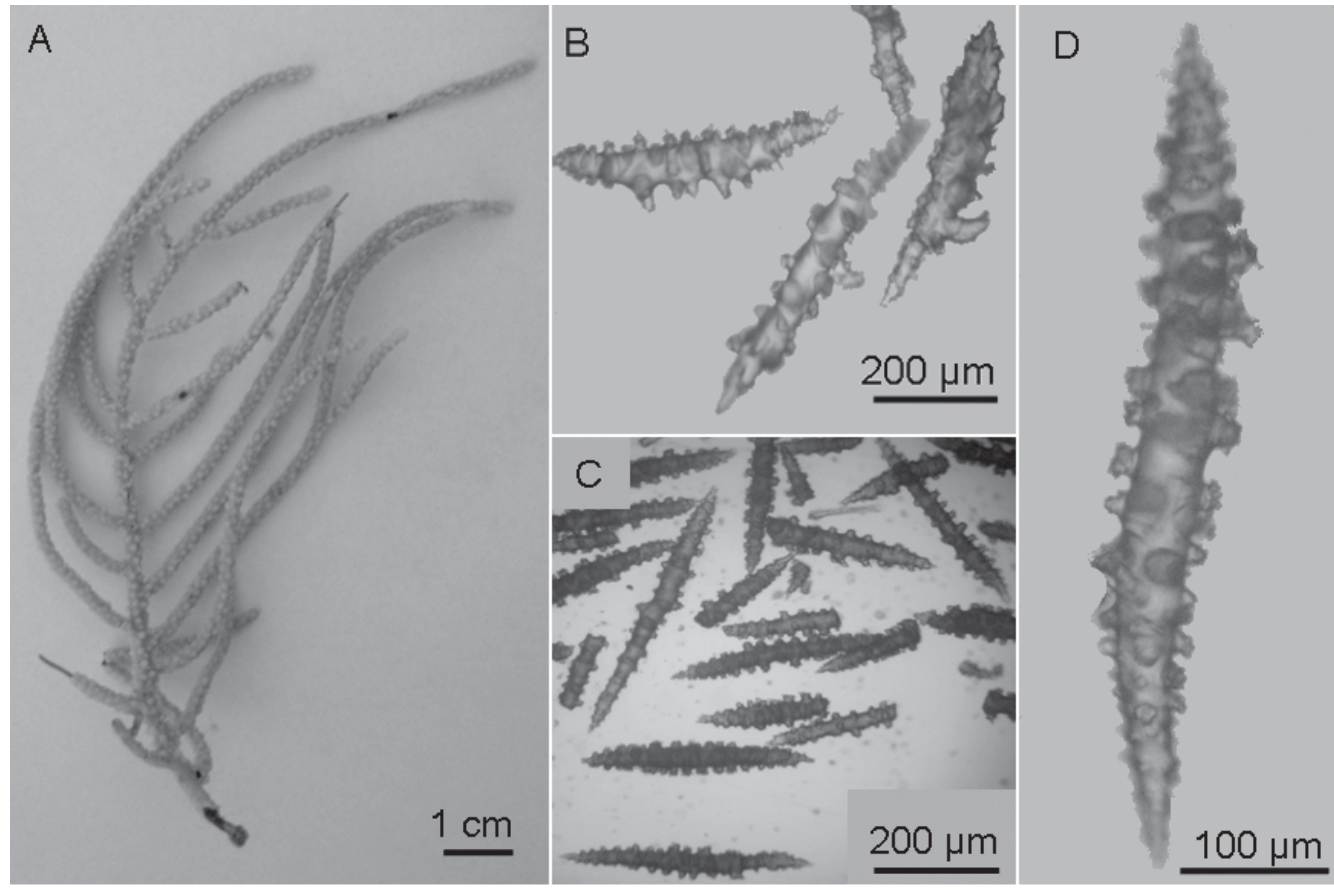

Fig. 7. Muriceopsis flavida (Lamarck, 1815) (CNI-DOCEAN no. 747). (A) Colony; (B) sclerites from cortex; (C) purple spindles from axial sheath; (D) outer cortex spindles 


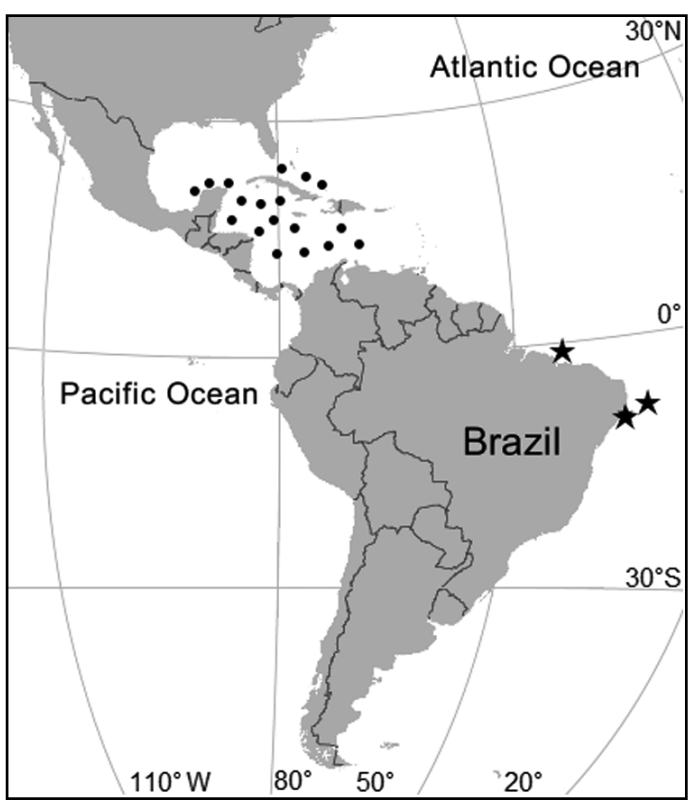

Fig. 8. Muriceopsis flavida. Distribution. (•) Previous records; ( $\star$ this study

Distribution. This species had previously only been recorded for the Caribbean Islands, except in Bermuda (Sánchez 2001). Samples were collected off the states of Maranhão, Pernambuco, and Alagoas, off the northeast coast of Brazil, representing a first record of this species in South Atlantic waters (Fig. 8).

Remarks. The specimens analyzed suggest that this species can be distinguished from the others in the genus due to its pinnate pattern with sparse branches, the elongated spindles on the outer cortex (which can reach $0.6 \mathrm{~mm}$ in length), and the purple spindles on the inner cortex.

\section{Family Nidaliidae Gray, 1869}

Genus Chironephthya Wright \& Studer, 1889

Diagnosis. See Fabricius \& Alderslade (2001).

\section{Chironephthya sp. (Fig. 9A-N)}

Material examined. Oceanographic survey 'Geo-

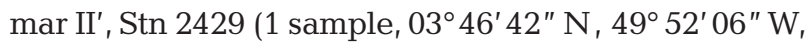
$111 \mathrm{~m}, 1970$, CNI-DOCEAN no. 449); 'Geomar III', Stn 152 (1 sample, $02^{\circ} 29^{\prime} 30^{\prime \prime} \mathrm{N}, 47^{\circ} 36^{\prime} 30^{\prime \prime} \mathrm{W}, 125 \mathrm{~m}$, 1971, CNI-DOCEAN no. 450); 'Norte/Nordeste I', Stn 1655 (1 sample, 06 $04^{\prime} 42^{\prime \prime} \mathrm{S}, 34^{\circ} 59^{\prime} \mathrm{W}, 25 \mathrm{~m}$, 1967, CNI-DOCEAN no. 452); 'Norte/Nordeste I', Stn 1783A (1 sample, $03^{\circ} 22^{\prime} \mathrm{N}, 48^{\circ} 55^{\prime} \mathrm{W}, 105 \mathrm{~m}$, 1967, CNI-DOCEAN no. 453).
Description. Ramified colonies, rigid in appearance (Fig. 9A). Polyps distributed along entire height of branches, sometimes crowded at ends but never restricted to them. Polyps upward, with one side pressed to axis. Stem striated. Colony 1.5 to $5.1 \mathrm{~cm}$ high, 0.4 to $2.8 \mathrm{~cm}$ wide; stem 0.1 to $0.8 \mathrm{~cm}$ wide. Calyces distinctive, sclerites organized as crown and points (Fig. 9B). Crown with 8 to 10 rows of elongated, sometimes curved spindles 0.47 to $0.62 \mathrm{~mm}$ high (Fig. 9H,I). Points are a pair of warted spindles bent at 1 end, 0.56 to $0.78 \mathrm{~mm}$ high (Fig. 9J), with accessory spindles among them. Spindles stouter in points than in crown. Large stem spindles $\leq 1.35 \mathrm{~mm}$ in length (Fig. 9C-G). Trunk spindles average 1.2 to $1.46 \mathrm{~mm}$ in height. Color: orange to red with calyces bearing white sclerites.

Distribution. Japan (Wright \& Studer 1889), Bay of Bengal (Indian Ocean), Admiralty Islands (Pacific Ocean), Macclesfield Bank and Tizard Reef (China Sea; Harrison 1908); Nan Wan Bay (Taiwan; Benayahu et al. 2004); Gulf of Mexico (Cairns \& Bayer 2009). This study reports the first record of this genus in South Atlantic waters, from samples collected from the Brazilian coast (states of Amapá, Pará, and Rio Grande do Norte; Fig. 10).

Remarks. The genus Chironephthya has already been discussed in the literature, especially regarding its similarity to the previously described genus Siphonogorgia Kölliker, 1874. Wright \& Studer (1889) mentioned the similarity between these genera, yet distinguished them after considering that in the new genus the polyps were distributed along the entire colony and were less retractile than in Siphonogorgia.

Hickson (1903) observed that the distinction by Wright \& Studer (1889) did not suffice because in Siphonogorgia pustulosa Studer, 1889, S. miniacea Kükenthal, 1896 and S. cylindrica Kükenthal, 1896, the polyps occur entirely along the branches, as in Chironephthya. Thus, that author suggested maybe considering Chironephthya and Siphonogorgia as a single genus. However, he also listed the following reasons for keeping them separate: Chironephthya could encompass the species whose ramification pattern resembles that of Nephthya spp. (with complete retraction of anthocodiae rare in preserved specimens and with 4 main sclerites organized into a chevron at the anthocodiae points), while the name Siphonogorgia should be for species that are more massive, gorgonian-like, with an anthocodiae capable of completely retracting into the coenenchyma and with anthocodial sclerites irregularly disposed or organized in a fan-like manner. 


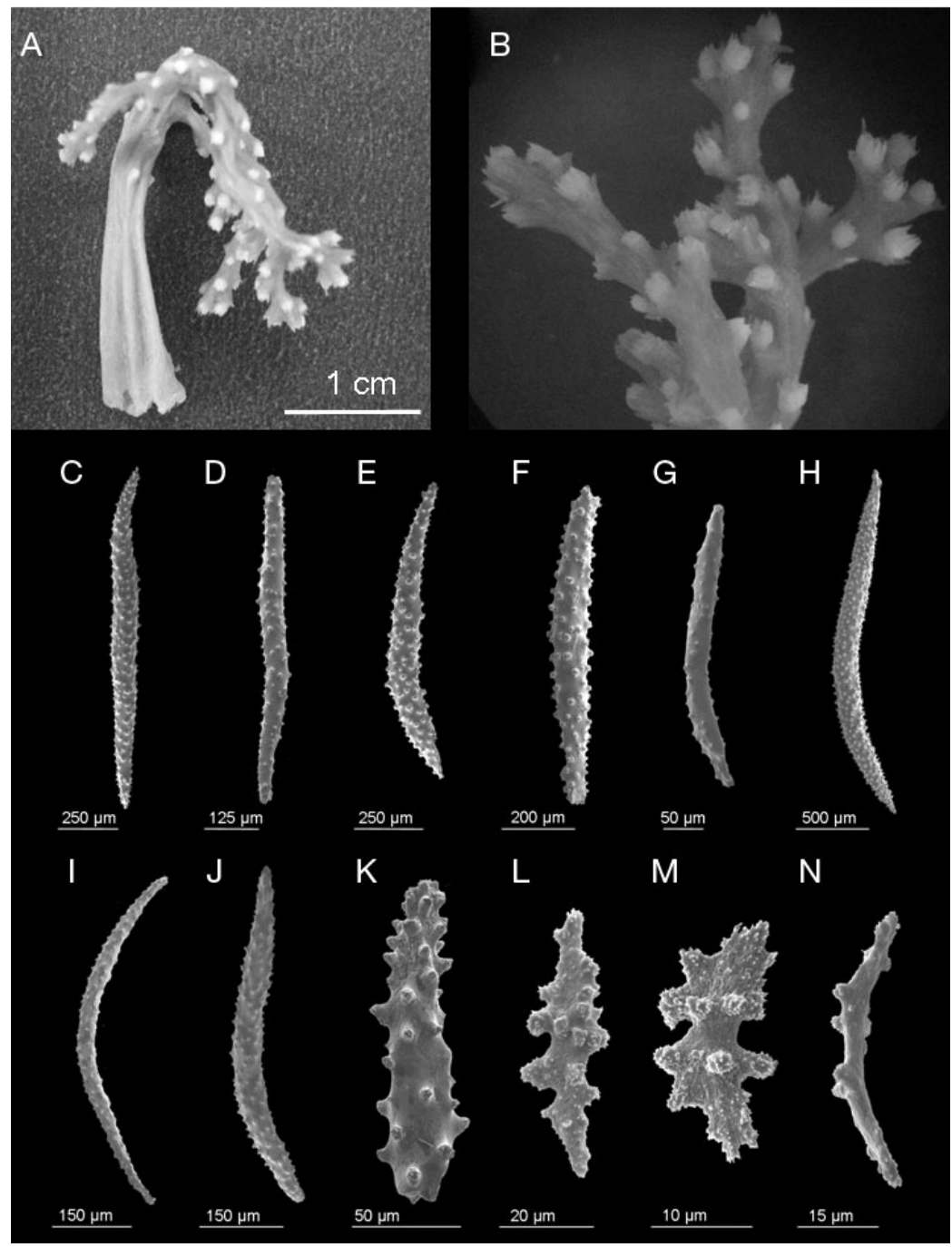

Fig. 9. Chironephthya sp. (CNI-DOCEAN no. 452). (A) Colony; (B) colony in detail; (C-N) SEM: (C-G) sclerites from stalk; (H) trunk; (I) collaret; (J) points; $(\mathrm{K})$ tentacle, $(\mathrm{L}-\mathrm{N})$ polyps
Thompson \& Simpson (1909) studied many specimens from both genera and concluded that the supposedly distinctive features were not satisfactory; thus, they maintained the name Siphonogorgia and included the Chironephthya species in this genus. Chalmers (1929) later described 9 species within the genus Siphonogorgia and also agreed that species from both genera should be included in it. Additionally, Deichmann (1936) described 2 species of the genus Neospongodes Kükenthal 1903 - N. agassizii and N. caribaeathat were later transferred to the genus Siphonogorgia by Bayer (1961).

Bayer (1981) suggested that Siphonogorgia and Chironephthya were synonyms; however, a few years later, Verseveldt \& Bayer (1988) presented the genera separately in a key for Nidaliidae based on whether the polyps were distributed or not along the entire colony (including the branches and main stem). Fabricius \& Alderslade (2001) also kept them separate according to polyp distribution. These authors considered that in Siphonogorgia the polyps may occur on most of the branches or may be restricted to the terminal branches; in Chironephthya, however, they are generally only found on terminal branches, although in some species they can be found on the main branches and occasionally on the upper stem.

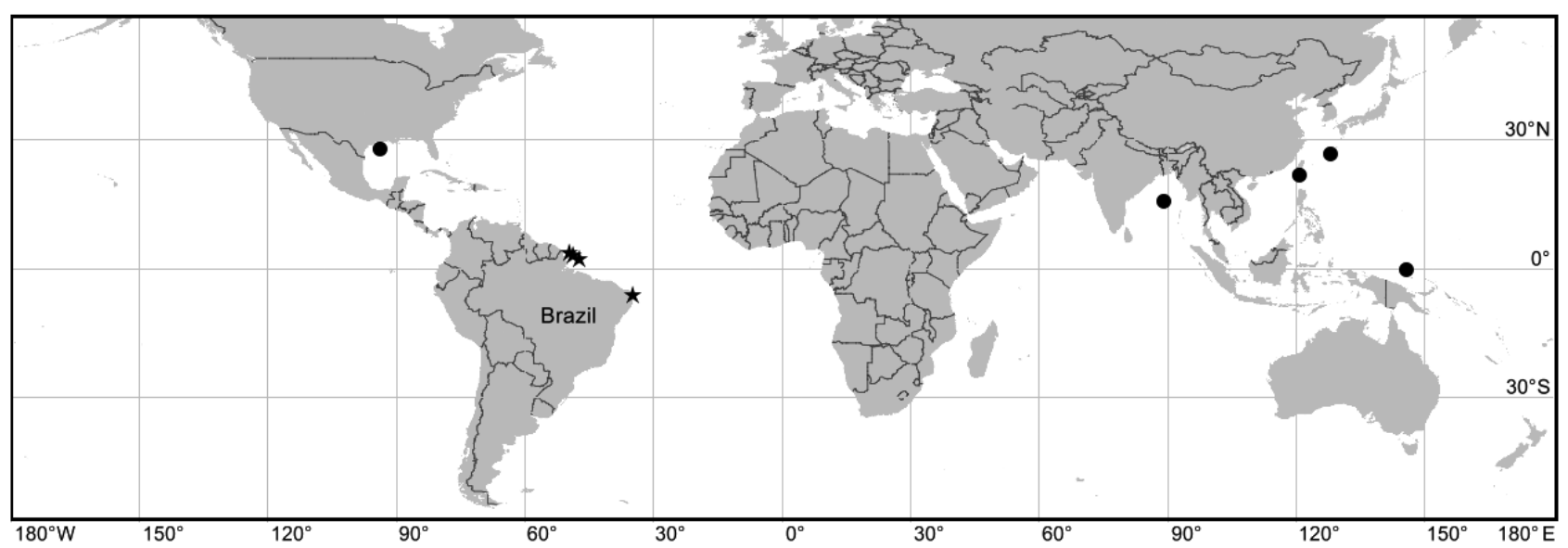

Fig. 10. Chironephthya spp. Distribution. (•) Previous records; $(\star)$ this study 

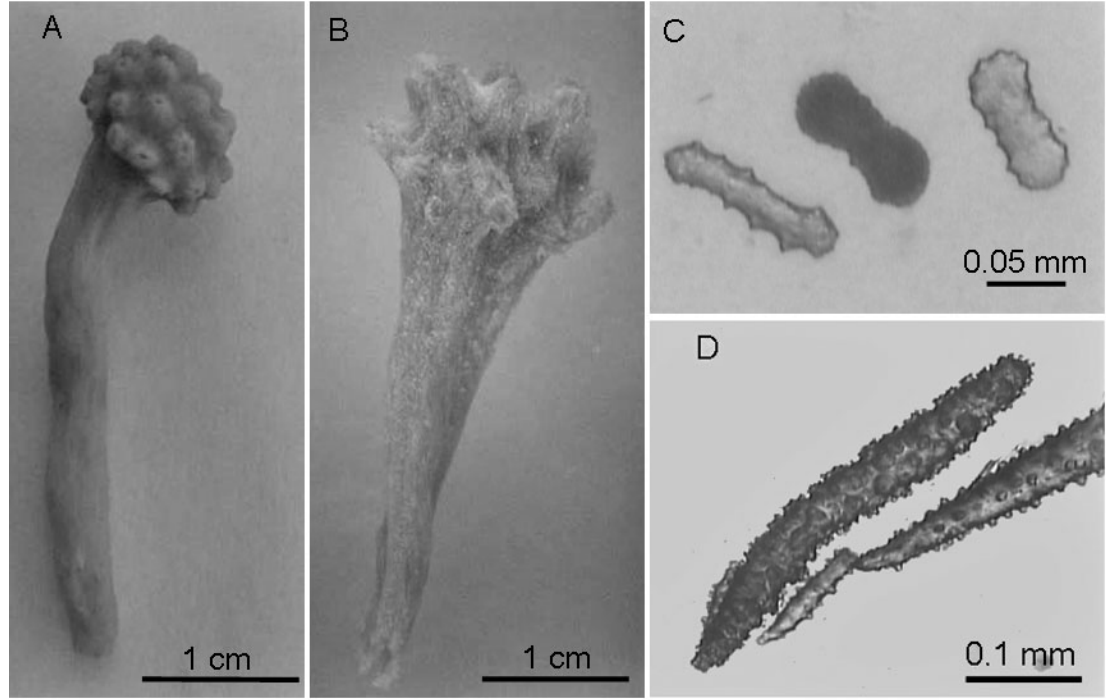

Fig. 11. Nidalia spp. (A) N. occidentalis Gray, 1835, CNI-DOCEAN no. 460. (B) Nidalia sp; (C) spindles from stalk of Nidalia sp.; (D) sclerites from introvert of Nidalia sp.

Cairns \& Bayer (2009) quoted Deichmann (1936) regarding species of Chironephthya: C. agassizii (Deichmann, 1936) and C. caribaea (Deichmann, 1936) for the Gulf of Mexico. This was the first mention of such a combination since Bayer (1961).

Some lots analyzed in this study still have an original label that identifies the colonies as Chironephthya sp. (= Siphonogorgia). This identification was possibly realized by Dr. F. Bayer, as these lots were once loaned to the Smithsonian Institution (Washington, DC).

Based on the above, there is a clear need to review both genera in order to determine their status more precisely. We did not identify species from these genera down to the species level because of the conflicts discussed here and the great number of species described for both genera (many of them only feebly described and/or illustrated); thus, identification at the species level is not viable at this time.

Here we decided to keep the genera separated as shown by Verseveldt \& Bayer (1988) and Fabricius \& Alderslade (2001), using polyp distribution as the main distinctive trait (along the trunk and main branches in Chironephthya and clustered and restricted to the ends in Siphonogorgia).

\section{Genus Nidalia Gray, 1835}

Nidalia occidentalis Gray, 1835 (Fig. 11A)

Diagnosis. See Verseveldt \& Bayer (1988).

Material examined. Oceanographic survey 'Geomar III', Stn 208 (1 sample, 04 52' N, 50³1' 30" W,
118 m, 1971, CNI-DOCEAN no. 460).

Description. Capitulum mushroom-shaped, distinctly projecting beyond stalk (Fig. 11A). Anthocodiae retracted. Crown approximately 15 rows deep and points in 2 to 3 pairs of spindles arranged in a chevron, with accessory spindles. Spindles curved in crown, 0.52 to $0.7 \mathrm{~mm}$ long. Colony $5 \mathrm{~cm}$ high, $4.5 \mathrm{~cm}$ stalk with 1.15 to 2.05 $\mathrm{mm}$ long spindles. Capitulum $0.5 \mathrm{~cm}$ high and $1.1 \mathrm{~cm}$ wide, with 0.72 to $1.22 \mathrm{~mm}$ long spindles (smaller ones rare). Color: orange with white calyces.

Distribution. From South Carolina (USA) to Barbados (Bayer 1961); the Gulf of Mexico (Brooke \& Schroeder 2007, Cairns \& Bayer 2009); Guyana and Surinam (Verseveldt 1978); and Colombia (Nidalia cf. occidentalis; Reyes et al. 2005). The specimens were collected off the state of Amapá, east of the Cabo Orange National Park, Brazil. This is the first record for this species in Brazil (Fig. 12).

Remarks. Nidalia occidentalis distinguishes itself from the other species in this genus mostly by having a mushroom-shaped polyparium; 15 or more rows of spindles in the crown; introverted without sclerites or with some scales reaching $0.10 \mathrm{~mm}$ at the proximal

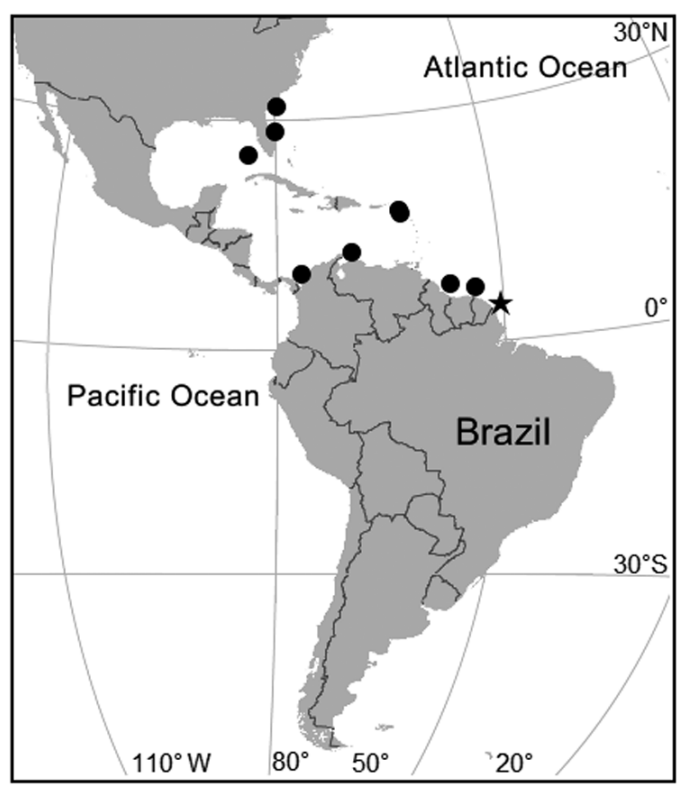

Fig. 12. Nidalia occidentalis. Distribution. (•) Previous records; $(\star)$ this study 


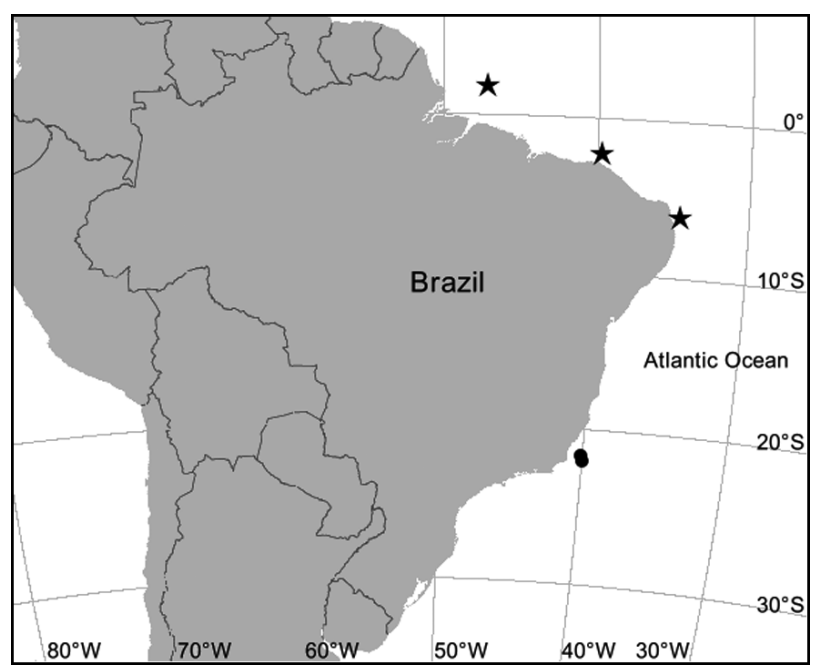

Fig. 13. Nidalia spp. Distribution along Brazilian coast. (•) Previous records (Nidalia sp.); ( $\star$ ) this study (Nidalia sp. and N. occidentalis)

region (Verseveldt \& Bayer 1988). Among the other species in the genus, the most morphologically similar is $N$. deichmannae Utinonmi 1954. However, $N$. occidentalis differs from it mostly by having spindles from coenenchyma reaching $2 \mathrm{~mm}$ long, while in $N$. deichmannae they can reach $5 \mathrm{~mm}$ in length, having a 'length:diameter' ratio of the sclerites of 6:1 in $N$. occidentalis and 4:1 in $N$. deichmannae. Utinomi (1958) affirmed that these 2 species are so similar that it was not possible to separate them at the species level. Despite that, Verseveldt \& Bayer (1988) decided to keep both species valid. The fact that the specimen has been collected off the state of Amapá reinforces this identification, as there are already records of this species as far as Surinam.

\section{Nidalia sp. (Fig. 11B-D)}

Material examined. Oceanographic survey 'Canopus', Stn $7\left(02^{\circ} 10^{\prime} \mathrm{S}, 39^{\circ} 50^{\prime} \mathrm{W}, 65 \mathrm{~m}, 1965-66\right.$, CNIDOCEAN no. 461); oceanographic survey 'Norte/ Nordeste I', Stn 1655 (06 04' 07" S, 34 59' W, 25 m, 1967, CNI-DOCEAN no. 462); Oceanographic survey

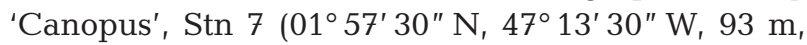
1967, CNI-DOCEAN no. 463).

Description. Capitulum torch-like (Fig. 11B). Colony up to $1.8 \mathrm{~cm}$ in length. Crown approximately 18 rows deep and points with 3 to 4 pairs of spindles, with intermediates among them. At least 2 kinds of dumbbells at introvert, both smooth, with medium constriction, but may be white and opaque or translucent yellow, with similar height $(0.06$ to $0.12 \mathrm{~mm}$ long); rods larger than dumbbells (0.13 to $0.17 \mathrm{~mm}$ long; Fig. 11C). Tentacles with small rods (0.04 to $0.06 \mathrm{~mm}$ long) and rare cross-like forms. Spindles in crown 0.95 to $1.27 \mathrm{~mm}$ long, 0.9 to $1.2 \mathrm{~mm}$ at points. Peduncle with small spiny spindles $(0.11$ to $0.16 \mathrm{~mm}$ long) and very large spindles (1.1 to $1.62 \mathrm{~mm}$ long; Fig. 11D). Color: orange.

Distribution. The genus has been reported in the Indian Ocean, Western Atlantic, and Western Pacific (Verseveldt \& Bayer 1988, López-González \& Gili 2008). In Brazil, there are records for the states of Espírito Santo and Rio de Janeiro (Castro et al. 2006). Here, specimens were collected from the states of Pará, Ceará, and Rio Grande do Norte, representing the first record of this genus for these locations, as well as for the northern region of Brazil (Fig. 13).

Remarks. To date, 13 species have been described for the genus Nidalia (López-Gonzáles \& Gili 2008). The key provided by Verseveldt \& Bayer (1988) includes 12 species, and leads directly to $N$. simpsoni through the followings features: (1) polyparium not laterally flattened, (2) sclerites in anthocodial crown 10 to 20 rows deep, (3) introverted with numerous small dumbbells. The species that is not listed in Verseveldt \& Bayer (1988) is N. aurantia López-González \& Gili, 2008, in which the introvert has curved spindles up to $0.5 \mathrm{~mm}$ high and whose crown is 13 to 17 rows deep.

Despite its similarity to $N$. simpsoni, the specimen analyzed here is possibly a juvenile form of another species of this genus, but we have identified it only to the genus level due to a lack of other specimens.

Castro et al. (2006) reported the first record for the Family Nidaliidae in Brazil, with the genus Nidalia; however, the specimens were also only identified to the genus level (Nidalia sp. 1 and sp. 2). Their specimens were collected off the states of Espírito Santo and Rio de Janeiro. The new Nidalia records presented here from the north and northeast regions of Brazil show geographic continuity with the records provided by Castro et al. (2006) from the Brazilian southeast region, and fill in part of the gaps in the distribution of this family along the tropical and subtropical West Atlantic waters (South Carolina, USA, to Rio de Janeiro, Brazil).

\section{FINAL CONSIDERATIONS}

The new records that have been presented here show the importance of oceanographic expeditions as an opportunity to collect marine organisms in places with limited access. We have also demon- 
strated the value of analyzing organisms kept in scientific collections; although these organisms may be stored for years before being studied, they sometimes hold essential scientific information such as new taxonomic records and even new taxa. Such studies can help fill in many species' geographic distribution gaps and increase the knowledge on marine biodiversity in areas that are still understudied.

Acknowledgements. We thank FACEPE for the MSc research fellowship to B.M.N and the graduate fellowship to D.H.R.O. Thanks to C. Peixoto from the Centro de Tecnologias Estratégicas do Nordeste (CETENE) for SEM images and to A. Greenman for English correction. This work was supported in part by funds from the PADI Foundation.

\section{LITERATURE CITED}

Bayer FM (1949) The Alcyonaria of Bikini and other atolls in the Marshall group. Part I: the Gorgonacea. Pac Sci 3: 195-214

Bayer FM (1952) New western Atlantic records of octocorals (Coelenterata: Anthozoa), with descriptions of three new species. J Wash Acad Sci 42:183-189

Bayer FM (1956) Descriptions and redescriptions of the Hawaiian octocorals collected by the U.S. Fish Survey Steamer 'Albatross' (2. Gorgonacea: Scleraxonia). Pac Sci 10:67-95

Bayer FM (1959) Octocorals from Surinam and the adjacent coasts of South America. Stud Fauna Suriname Other Guyanas 3:1-43

Bayer FM (1961) The shallow-water Octocorallia of the West Indian region. Stud Fauna Curaçao Other Caribb Isl 12:i-viii, $1-373$

Bayer FM (1981) Key to the genera of Octocorallia exclusive of Pennatulacea (Coelenterata: Anthozoa), with diagnoses of new taxa. Proc Biol Soc Wash 94:902-947

Bayer FM (1992) Thelogorgia, a new genus of gorgonacean octocorals, with descriptions of four new species from the western Atlantic. Bull Mar Sci 49:506-537

Bayer FM, Grasshoff M, Verseveldt J (eds) (1983) Illustrated trilingual glossary of morphological and anatomical terms applied to Octocorallia. E. J. Brill, Leiden

Benayahu Y, Jeng MS, Perkol-Finkel S, Dai CF (2004) Soft corals (Octocorallia: Alcyonacea) from southern Taiwan. II. Species diversity and distributional patterns. Zool Stud 43:548-560

Brooke S, Schroeder WW, Hourigan TF, Bruckner AW, Dorr G (2007) State of deep coral ecosystems in the Gulf of Mexico region: Texas to the Florida straits. In: Lumsden SE, Hourigan TF, Bruckner AW, Dorr G (eds) The state of deep coral ecosystems of the United States. NOAA Tech Memo CRCP-3, p 271-306. Available at www.coris.noaa. gov/activities/deepcoral_rpt/Chapter7_GulfofMexico.pdf (accessed 21 March 2010)

Cairns SD, Bayer FM (2009) Octocorallia (Cnidaria) of the Gulf of Mexico. In: Felder DL, Camp DK (eds) Gulf of Mexico - origins, waters, and biota, Vol 1. Biodiversity. Texas A\&M University Press, College Station, TX, p 312-331

Castro CB, Pires DO, Medeiros MS, Loiola LL, Arantes
RCM, Thiago CM, Berman E (2006) Filo Cnidaria. Corais. In: Lavrado HP, Ignacio BL (eds) Biodiversidade bentônica da região central da Zona Econômica Exclusiva Brasileira, Book 18. Museu Nacional, Rio de Janeiro, p 147-192

Castro CB, Medeiros MS, Loiola LL (2010) Octocorallia (Cnidaria: Anthozoa) from Brazilian reefs. J Nat Hist 44:763-827

Chalmers D (1929) The Alcyonarian genus Siphonogorgia, with descriptions of new species. Proc R Phys Soc Edinb 21:159-169

Daly M, Brugler MR, Cartwright P, Collins AG and others (2007) The phylum Cnidaria: a review of phylogenetic patterns and diversity 300 years after Linnaeus. Zootaxa 1668:127-182

Deichmann E (1936) The Alcyonaria of the western part of the Atlantic Ocean. Mem Mus Comp Zool 53:253-308

Fabricius K, Alderslade P (2001) Soft corals and sea fans: a comprehensive guide to the tropical shallow water genera of the Central West Pacific, the Indian Ocean and the Red Sea. Australian Institute of Marine Science, Townsville

Grasshoff M (1977) Die Gorgonarien des östlichen Nordatlantik und des Mittelmeeres. III. Die Familie Paramuriceidae (Cnidaria, Anthozoa). 'Meteor' Forschungsergeb D 27:5-76

Harrison RM (1908) Some new Alcyonaria from the Indian and Pacific Oceans, preliminary notice. Zool J Linn Soc 30:185-190

Hickson SJ (1903) The Alcyonaria of the Maldives. Part I. The genera Xenia, Telesto, Spongodes, Nephthya, Paraspongodes, Chironephthya, Siphonogorgia, Solenocaulon, and Melitodes. In: Gardiner JS (ed) The fauna and geography of the Maldive and Laccadive Archipelagoes. Cambridge University, Cambridge, p 473-502

Kempf M (1970) Notes on the benthic bionomy of the N-NE Brazilian shelf. Mar Biol 5:213-224

Kinoshita K (1910) On the Keroeididae, a new family of Gorgonacea, and some notes on the Suberogorgiidae. Annot Zool Jpn 7:223-230

> López-González PJ, Gili JM (2008) A new species of Nidalia Gray, 1835 from mid-Atlantic seamounts (Octocorallia, Alcyonacea, Nidaliidae). Helgol Mar Res 62:389-392

Reyes J, Santodomingo N, Gracia A, Borrero-Pérez G and others (2005) Southern Caribbean azooxanthellate coral communities off Colombia. In: Freiwald A, Murray RJ (eds), Cold-water corals and ecosystems. Springer, Berlin, Heidelberg, p 309-330

Sánchez JA (2001) Systematics of the southwestern Caribbean Muriceopsis Aurivillius (Cnidaria: Octocorallia), with the description of a new species. Bull Biol Soc Wash 10:160-180

Sánchez JA, Wirshing HHA (2005) Field key to the identification of tropical western Atlantic zooxanthellate octocorals (Octocorallia: Cnidaria). Caribb J Sci 41:508-522

Thomson JA, Simpson JJ (1909) An account of the Alcyonarians collected by the Royal Indian Marine Survey Ship Investigator in the Indian Ocean; with a report on the species of Dendronephthya by W.D. Henderson. II. The Alcyonarians of the littoral area. The Indian Museum, Calcutta

Tixier-Durivault A, D'Hondt M (1974) Nouvelles récoltes d'octocoralliaires à Madagascar. Téthys 5:251-266

Utinomi H (1958) A revision of the genera Nidalia and Bellonella, with an emendation of nomenclature and taxo- 
nomic definitions of the family Nidaliidae (Octocorallia, Alcyonacea). Bull Br Mus (Nat Hist) Zool 5:101-121

van Ofwegen LP (1990) Notes on the Keroeididae (Anthozoa: Gorgonacea) collected in 1963 and 1964 by the international Indian Ocean expedition of the R/V 'Anton Bruun', in the Indian Ocean, with the description of a new species, Lignella hartogi. Zool Meded 63:163-168

van Ofwegen LP (1994) Pseudothelogorgia, a new genus of Gorgonacean octocorals from the Indian Ocean. Precious Coral Octocoral Res 3:389-392

Verseveldt J (1978) On some Telestacea and Alcyonacea (Coelenterata: Octocorallia) from the West Indian region. Zool Meded 53:41-47

Editorial responsibility: Hans Heinrich Janssen, Oldendorf/Luhe, Germany
Verseveldt J, Bayer FM (1988) Revision of the genera Bellonella, Eleutherobia, Nidalia and Nidaliopsis (Octocorallia: Alcyoniidae and Nidaliidae), with descriptions of 2 new Genera. Zool Verh (Leiden) 245:1-131

Williams GC (1992) The Alcyonacea of southern Africa. Gorgonian octocorals (Coelenterata, Anthozoa). Ann S Afr Mus 101:181-296

Wing BL, Barnard DR (2004) A field guide to Alaskan corals. NOAA Tech Memo NMFS-AFSC-146. US Department of Commerce, Springfield, VA

Wright EP, Studer T (1889) Report on the Alcyonaria collected by H.M.S. Challenger during the years 1873-1876. Zoology 31: i-lxxvii, 1-314

Submitted: April 14, 2010; Accepted: June 20, 2011

Proofs received from author(s): September 9, 2011 